\title{
FISSILE MASS FLOW MONITOR GAMMA RAY DETECTOR SYSTEM DESIGNED FOR LARGE-SIZE PROCESS PIPES
}

July 2004

Taner Uckan

Kim Castleberry José March-Leuba Danny Powell Joseph Glaser 


\title{
DOCUMENT AVAILABILITY
}

Reports produced after January 1, 1996, are generally available free via the U.S. Department of Energy (DOE) Information Bridge:

Web site: http://www.osti.gov/bridge

Reports produced before January 1, 1996, may be purchased by members of the public from the following source:

\author{
National Technical Information Service \\ 5285 Port Royal Road \\ Springfield, VA 22161 \\ Telephone: 703-605-6000 (1-800-553-6847) \\ TDD: 703-487-4639 \\ Fax: $703-605-6900$ \\ E-mail: info@ ntis.fedworld.gov \\ Web site: http://www.ntis.gov/support/ordernowabout.htm
}

Reports are available to DOE employees, DOE contractors, Energy Technology Data Exchange (ETDE) representatives, and International Nuclear Information System (INIS) representatives from the following source:

Office of Scientific and Technical Information

P.O. Box 62

Oak Ridge, TN 37831

Telephone: 865-576-8401

Fax: 865-576-5728

E-mail: reports@adonis.osti.gov

Web site: http://www.osti.gov/contact.html

This report was prepared as an account of work sponsored by an agency of the United States government. Neither the United States government nor any agency thereof, nor any of their employees, makes any warranty, express or implied, or assumes any legal liability or responsibility for the accuracy, completeness, or usefulness of any information, apparatus, product, or process disclosed, or represents that its use would not infringe privately owned rights. Reference herein to any specific commercial product, process, or service by trade name, trademark, manufacturer, or otherwise, does not necessarily constitute or imply its endorsement, recommendation, or favoring by the United States government or any agency thereof. The views and opinions of authors expressed herein do not necessarily state or reflect those of the United States government or any agency thereof. 


\title{
Nuclear Science and Technology Division
}

\section{FISSILE MASS FLOW MONITOR GAMMA RAY DETECTOR SYSTEM DESIGNED FOR LARGE-SIZE PROCESS PIPES}

\author{
Taner Uckan, Kim Castleberry, José March-Leuba, and \\ Danny Powell (ORNL) \\ Joseph Glaser (DOE)
}

Date Published: July 2004

Presented at the

Institute of Nuclear Materials Management 45th Annual Meeting

July 18-22, 2004

Orlando Florida

Prepared by the

OAK RIDGE NATIONAL LABORATORY

Oak Ridge, Tennessee 37831-6423

managed by

UT-BATTELLE, LLC

for the

U.S. DEPARTMENT OF ENERGY

under contract DE-AC05-00OR22725 



\section{CONTENTS}

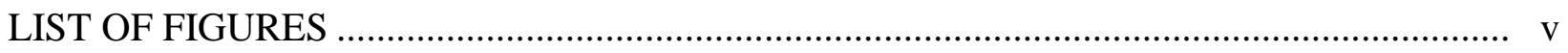

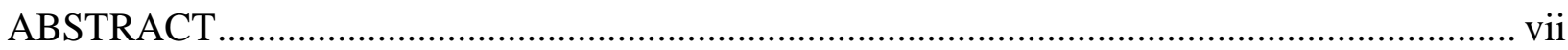

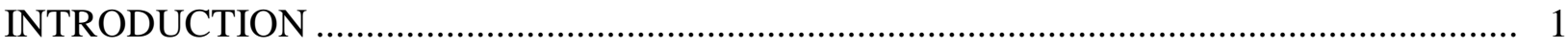

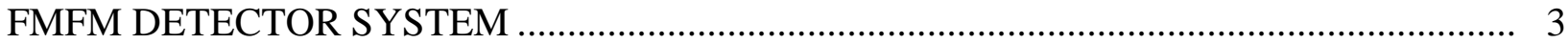

FMFM DETECTOR ELECTRONICS ….............................................................. 5

FMFM DETECTOR SYSTEM ENGINEERING DESIGN CHARACTERISTICS ................. 9

DUAL DETECTOR PERFORMANCE AND ENERGY CALIBRATION ............................. 13

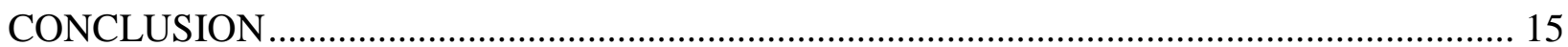

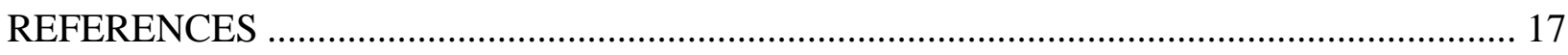

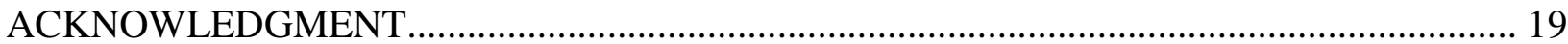





\section{LIST OF FIGURES}

Figure

Page

1. The FMFM system's operational principle is based on fission activation of $\mathrm{UF}_{6}$ gas in the flow stream

2. The measured FMFM detector signal waveform and the detector counts are collected every $100 \mathrm{~ms}$, as the shutter cycles

3. Major components of the FMFM system for an 8-in.-diam pipe

4. The peak photoefficiency of a bismuth germinate (BGO) crystal compared with that of a similarly sized sodium iodide (NaI) scintillation crystal

5. FMFM gamma ray detector is composed of a commercially available BGO scintillation detector (left) and a preamplifier (right)

6. FMFM detector housing for the dual BGO detectors, including the detector interface electronics card (DIEC) and the sensor network communication (SNC) card

7. Schematic block diagram of the FMFM detector electronics card (DIEC)

8. The custom-made detector interface electronics card and the sensor network communication (SNC) card that mounts on it..

9. FMFM detector system utilizes both low-energy and high-energy single-channel analyzers (SCAs)

10. FMFM detector assembly designed for 8-in.-diam $\mathrm{UF}_{6}$ process pipes

11. Cross-sectional view of the FMFM detector assembly around the process pipe 10

12. View of the FMFM detector housing showing the detector interface electronics card (DIEC) and the sensor network communication (SNC) card.

13. View of the FMFM detector assembly showing the detector signal and power distribution (DSPD) box and the additional lead gamma shielding located near the FMFM sources

14. Energy calibration plots for detectors A and B in the dual detector located in subassembly No. 1 



\begin{abstract}
This paper presents a detailed design description and the performance characteristics for a gamma ray detector system developed for the fissile mass flow monitor (FMFM) to be used on 8 -in.-diam process pipes. The FMFM continuously measures the ${ }^{235} \mathrm{U}$ fissile mass flow rate of a $\mathrm{UF}_{6}$ gas stream. It uses moderated and modulated ${ }^{252} \mathrm{Cf}$ neutron sources for fission activation of the $\mathrm{UF}_{6}$ gas. Four pairs of bismuth germinate (BGO) scintillation detectors are placed around the process pipe (on the top, bottom, front, and back) downstream of the neutron sources so that a high detection efficiency can be achieved for measuring the delayed gammas $(>0.3 \mathrm{MeV})$ emitted from the fission fragments in the stream.

The BGO crystal was selected because it is a novel scintillation material (rugged, nonhygroscopic, neutron-insensitive, high-density, and high-Z) with high absorption (stopping) power and because it has high peak photoefficiency for high-energy gammas. Each 4-in.-diam, 2-in.-thick BGO scintillation crystal is coupled to a 3-in.-diam photomultiplier tube (PMT). Both are shielded with lead to reduce the background signal. Each detector pair is housed in a metal enclosure that also contains an electronics board for signal shaping and counting. The front-end electronics boards independently amplify and shape the detector signals before they are summed. The combined signal is then fed into two single-channel analyzers (SCAs), which separate the pulses into low- and highenergy bands and subsequently determine the count rate in each band.

A local area network node for providing secure data transmission to the FMFM computer and a local temperature sensor are also part of each detector electronics board. The temperature response of the detector signal resulting from the intrinsic temperature coefficient of each BGO-PMT assembly is used to correct the system in real time by monitoring the $186-\mathrm{keV}$ spectrum line of ${ }^{235} \mathrm{U}$ obtained with the lower-energy SCA. The lower-energy SCA is also scanned during manual detector energy calibration to capture 186- or $96-\mathrm{keV}$ spectral lines from the $\mathrm{UF}_{6}$, depending upon its enrichment. The higherenergy SCA output provides for the measurement of the 0.3 - to 2-MeV delayed gamma ray signal from the fission fragments in the $\mathrm{UF}_{6}$ stream.
\end{abstract}





\section{INTRODUCTION}

The fissile mass flow monitor (FMFM) is designed to continuously measure the ${ }^{235} \mathrm{U}$ fissile mass flow rate of a $\mathrm{UF}_{6}$ gas stream. The fissile mass flow rate measurement principle relies on detecting "delayed" gamma rays, which are emitted from fission fragments carried by the $\mathrm{UF}_{6}$ flow. The fission events that produce the fragments are caused by active neutron interrogation. Neutron sources $\left({ }^{252} \mathrm{Cf}\right)$ are placed in annular sleeves filled with moderator material (high-density polyethylene) that surrounds the pipe, as illustrated schematically in Figure 1. A neutron-absorbing shutter is used to timemodulate the induced fission events (see Figure 1) to create a time signature in the $\mathrm{UF}_{6}$ gas flow. A gamma-ray-sensitive detector, located downstream of the sources (see Figure $1)$, measures delayed gamma rays ( $>0.3 \mathrm{MeV}$ ) emitted by the resulting fission fragments. Then the FMFM determines the fissile mass flow rate from two independent measurements (see Figure 2): (1) the observed delay in the time-correlated measurement between the source modulator and the detector signal provides the velocity of the $\mathrm{UF}_{6}$, and (2) the signal's amplitude is related to the ${ }^{235} \mathrm{U}$ concentration in the $\mathrm{UF}_{6}$. The details of the FMFM models employed to predict the detector response are discussed in an earlier publication [1]. The earlier FMFM was designed for 4-in.-diam $\mathrm{UF}_{6}$ process pipes. In this paper, a detailed design description and the performance characteristics are presented for the FMFM gamma ray detector system developed to be used on 8-in.-diam process pipes (see Figure 3).

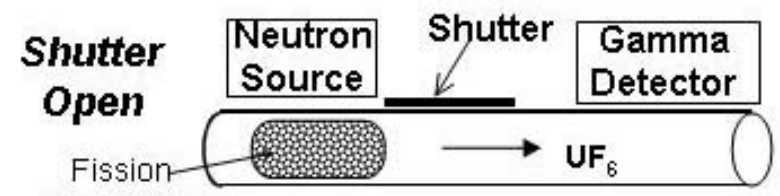

Fragments

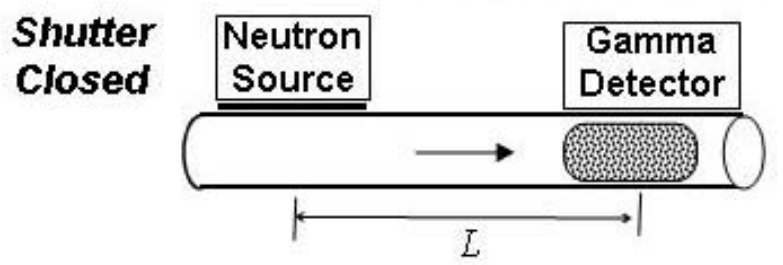

Velocity $=$ L/time of flight

${ }^{235} \mathrm{U}$ concentration $\propto$ detector signal intensity Fissile mass flow rate $(\mathrm{g} / \mathrm{s})=$ Velocity $(\mathrm{m} / \mathrm{s}) \times{ }^{235} \mathrm{U}$ Concentration $(\mathrm{g} / \mathrm{m})$

Fig. 1. The FMFM system's operational principle is based on fission activation of $\mathbf{U F}_{\mathbf{6}}$ gas in the flow stream. When the shutter opens (top), fissions are induced, and the stream carries the fragments downstream. When it closes (bottom), gamma rays $(>300 \mathrm{keV})$ emitted by the fragments are detected downstream. 


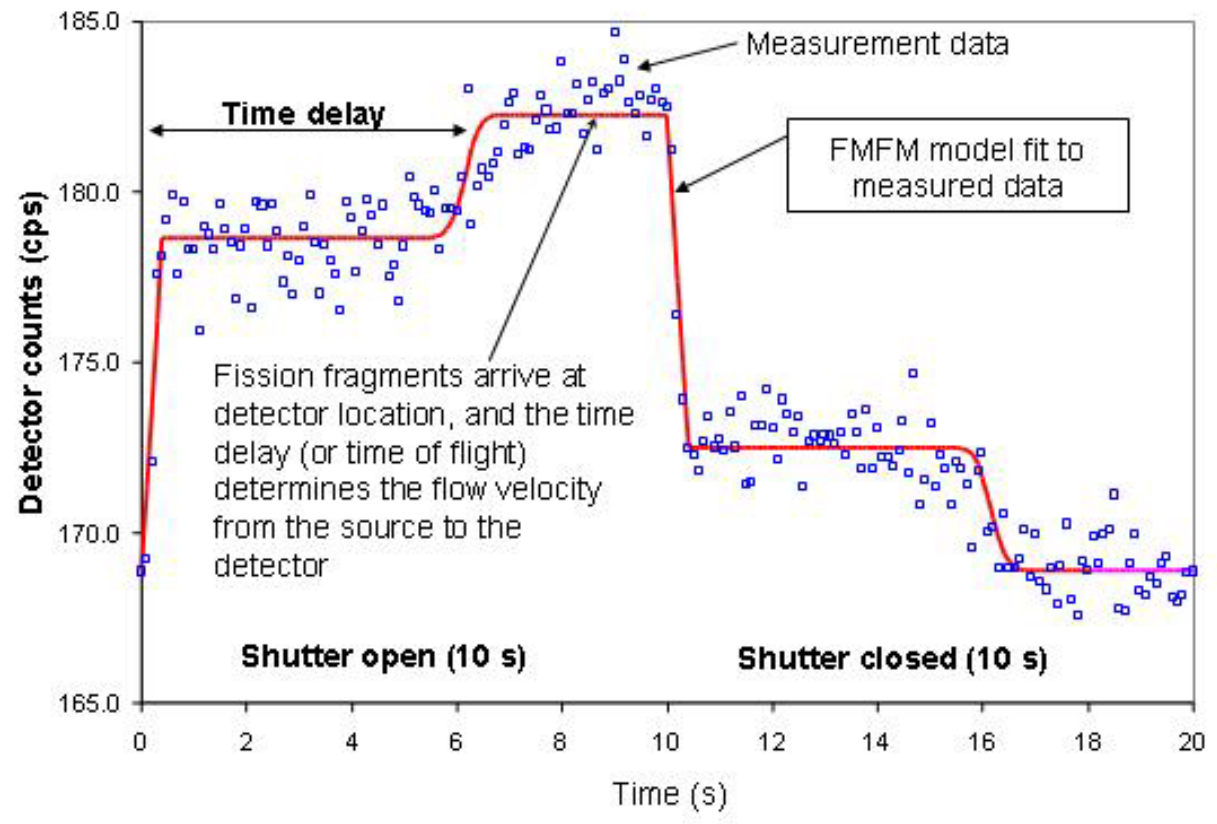

Fig. 2. The measured FMFM detector signal waveform and the detector counts are collected every $100 \mathrm{~ms}$, as the shutter cycles.

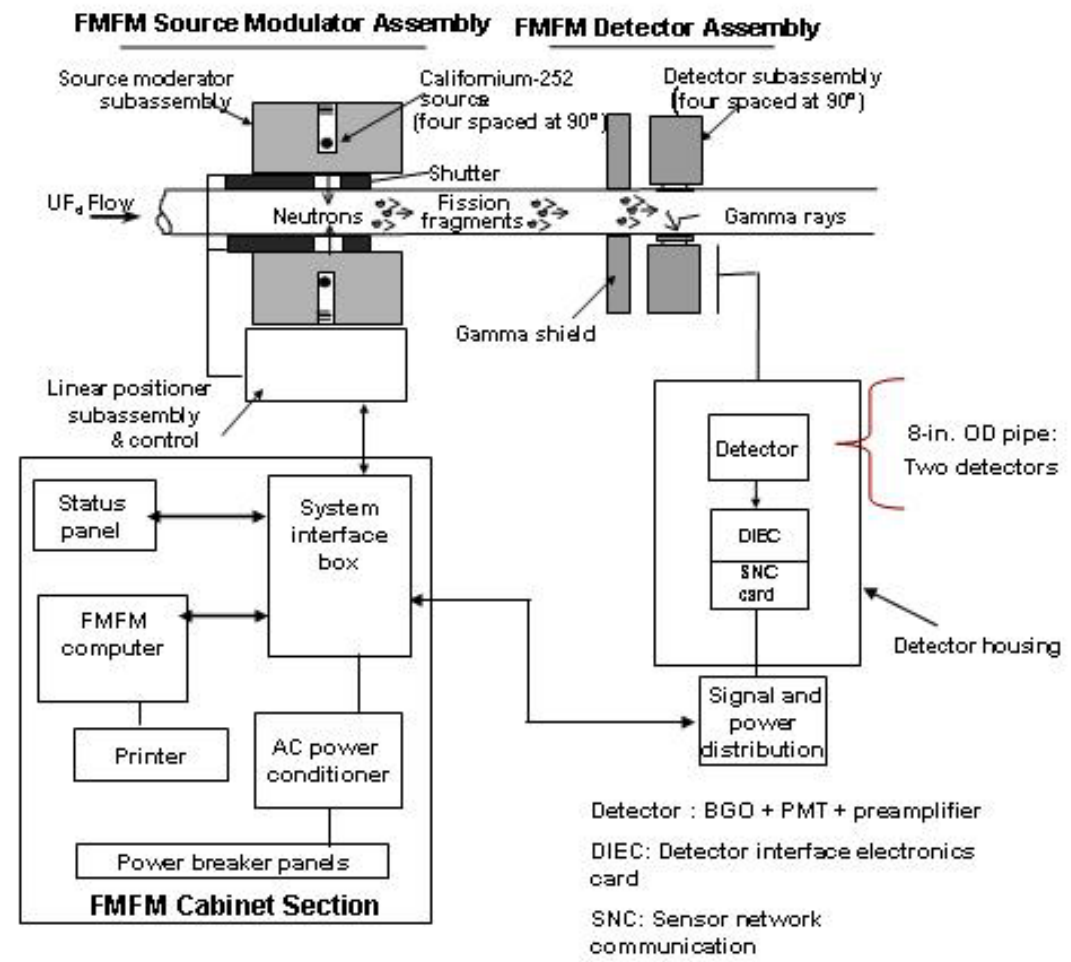

Fig. 3. Major components of the FMFM system for an 8-in.-diam pipe. The source moderator is covered with lead and lithiated poly shielding to meet the facility dose rate requirement $(0.3 \mathrm{mrem} / \mathrm{h}$ at $1 \mathrm{~m})$. 


\section{FMFM DETECTOR SYSTEM}

In the case of low-enriched $\mathrm{UF}_{6}$ flow measurements, or for short process durations, the detector signal, $N_{\mathrm{s}}$, from the delayed gamma rays needs to be increased in order to achieve the measurements within a short period of time (less than the process duration) with statistically acceptable measurement results (measurement confidence level $>90 \%$ ). This is necessary because the measurement convergence time $\tau_{\mathrm{c}} \sim N_{\mathrm{b}} / N_{\mathrm{s}}{ }^{2}$, where $N_{\mathrm{b}}$ is the room background. Increasing the detector signal is possible only by increasing the delayed gamma ray source that results from the fission activation of the $\mathrm{UF}_{6}$ flowing in the process pipe. Using a higher neutron source strength of ${ }^{252} \mathrm{Cf}$ is not a viable option because the facility dose rate requirement must be maintained. Therefore, the desired higher detector signal, $N_{\mathrm{s}}$, is achieved by increasing the active volume of the fission process (i.e., using a larger-diameter process pipe) and thus having a higher volume of fission fragments flowing in the $\mathrm{UF}_{6}$ gas stream. To take advantage of the large-diameter pipe, more detectors are needed than the number used in the system built for a 4-in.-diam pipe. Increasing the number of detectors results in a higher detection efficiency, which results in a higher detection signal, $N_{\mathrm{s}}$, because the value of $N_{\mathrm{s}}$ is related to the solid angle, $\Omega_{\mathrm{d}}$, of the detector as seen from the gamma ray source. (Here, $\Omega_{\mathrm{d}}$ is defined by an integral over the detector area that faces the gamma ray source.)

As shown in Figure 3, four pairs of bismuth germinate (BGO) scintillation detectors are placed around the process pipe (on the top, bottom, front, and back) downstream of the neutron sources to obtain a higher detection efficiency for measuring the delayed gammas. The BGO scintillation crystal was selected because it is a novel scintillation material with high absorption (stopping) power due to its high density $\left(\rho=7.3 \mathrm{~g} / \mathrm{cm}^{3}\right)$ and because the high atomic number of bismuth $(Z=83)$ results in high peak photoefficiency for the high-energy $(>0.3 \mathrm{MeV})$ delayed gamma rays. Figure 4 illustrates the peak photoefficiency of BGO compared with that of a sodium iodide (NaI) scintillation crystal of similar size [2]. In addition, BGO has very low neutron activation characteristics. This is an important feature because the detectors are placed close to the source modulator that houses the ${ }^{252} \mathrm{Cf}$-neutron sources (see Figure 3). Each 4-in.-diam, 2-in.-thick BGO scintillation crystal is coupled to a 3-in.-diam photomultiplier tube (PMT) housed in a container made of a nonmagnetic material, as shown in Figure 5 (St. Gobain Crystals and Detectors, Inc., Newbury, Ohio). The PMT dynodes are biased with a commercially available ORTEC Model 276 tube base that also contains signalintegrating preamplifier circuitry, which has very fast rise time $(<100$ nanoseconds) with a decay time constant of 50 microseconds (available from ORTEC, Oak Ridge, Tenn.). The PMT operation requires high voltage, $+1000 \mathrm{Vdc}$; the detector preamplifier operates with \pm 24 Vdc.

Figure 6 is a diagram of one detector housing, or subassembly, for an 8-in.-diam process pipe. Each detector housing is designed to hold dual detectors (labeled "Detector A" and "Detector B"). One housing is placed on the top, bottom, front, and back of the process pipe. This design is an extension of the one developed for the 4-in.-diam pipe FMFM, in which a single detector in each housing provides the optimum configuration for the pipe size. For the 8-in. pipe, high detector efficiency is achieved by increasing the number of detectors from a total of four to eight in the FMFM assembly. 


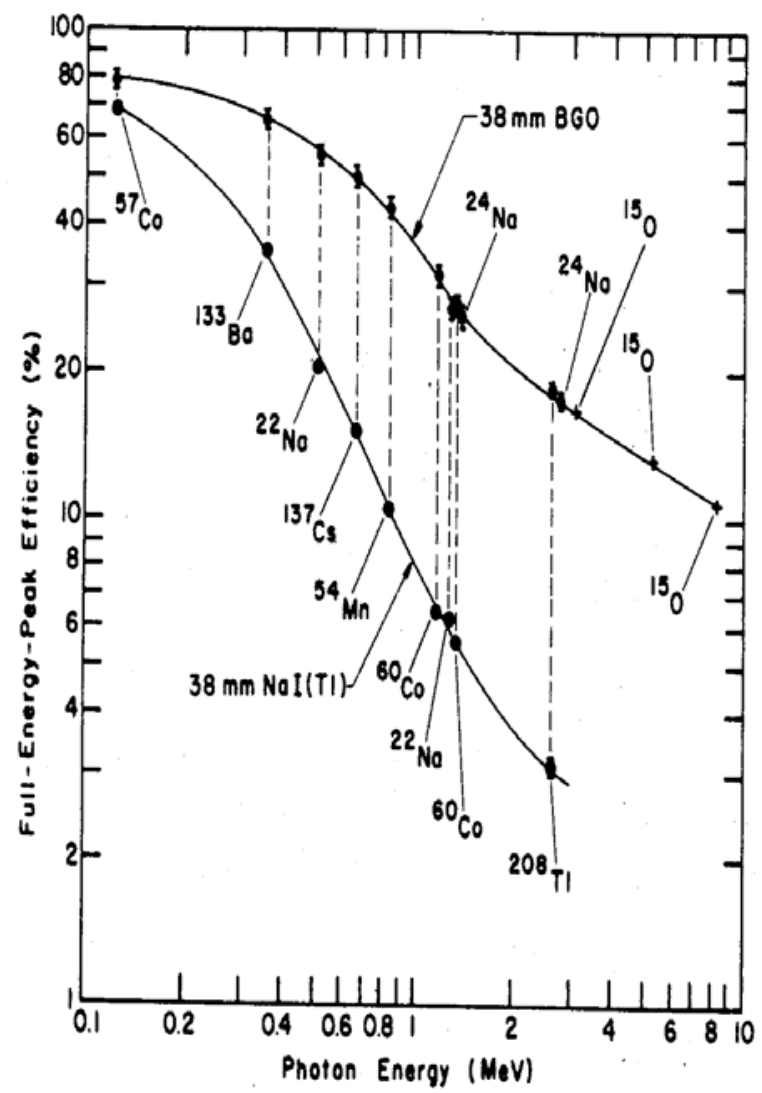

Fig. 4. The peak photoefficiency of a bismuth germinate (BGO) crystal compared with that of a similarly sized sodium iodide (NaI) scintillation crystal. The peak photoefficiency of BGO is better for detecting high-energy gammas. (Source: G. P. Knoll, Radiation Detection and Measurements, 3rd Edition, John Wiley and Sons, New York, 2000).

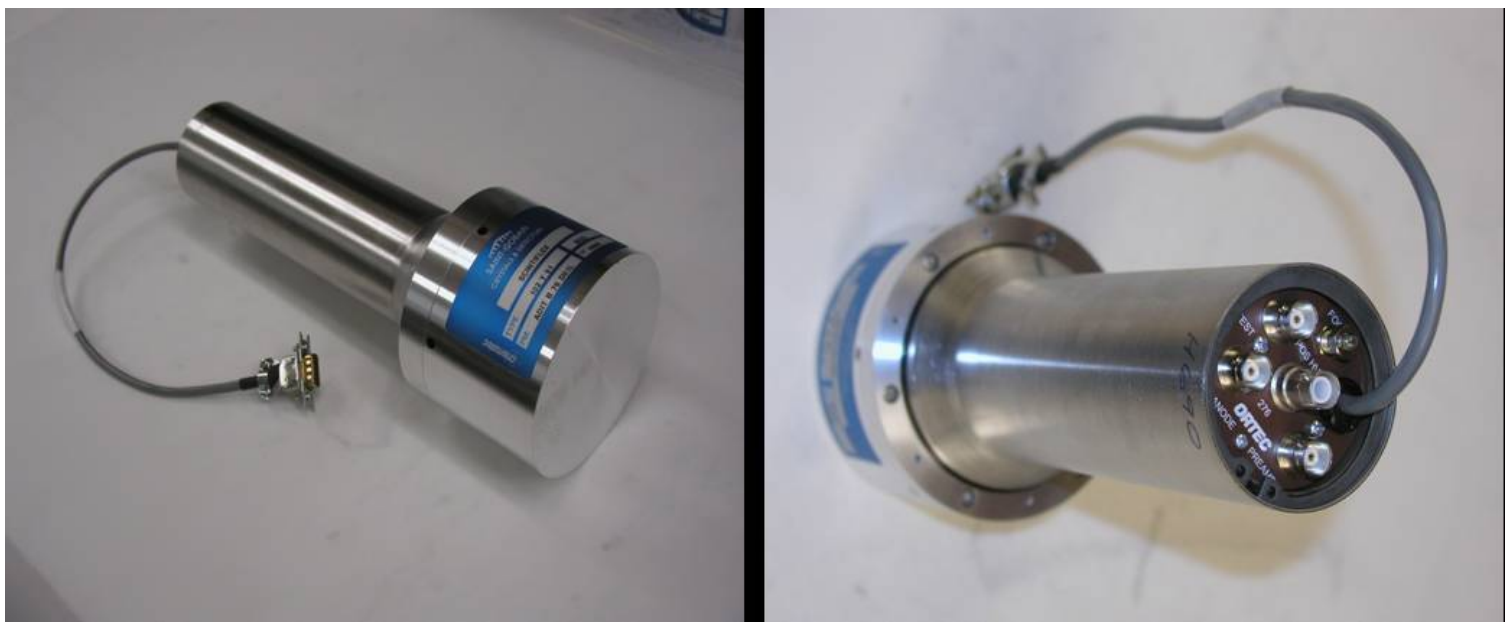

Fig. 5. FMFM gamma ray detector is composed of a commercially available BGO scintillation detector (left) and a preamplifier (right). 


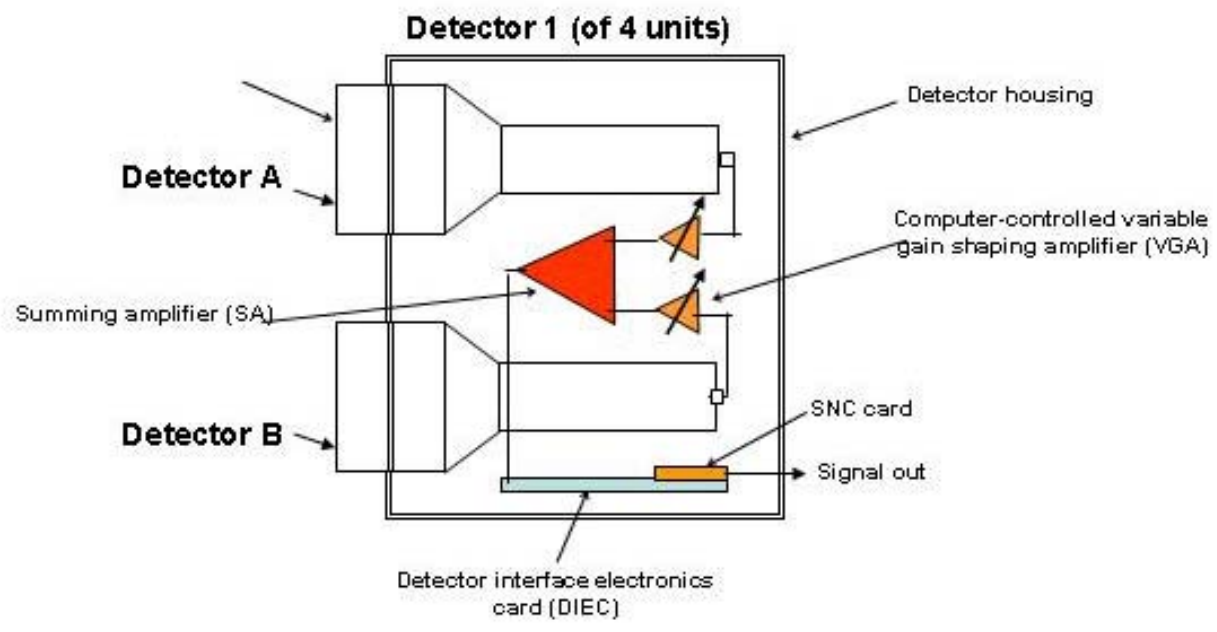

Fig. 6. FMFM detector housing for the dual BGO detectors, including the detector interface electronics card (DIEC) and the sensor network communication (SNC) card. Each detector is composed of a 4-in.-diam, 2-in.-thick bismuth germinate detector, a photomultiplier tube, and a preamplifier. The variable gain shaping amplifier and the summing amplifier are parts of the DIEC; they are shown separately for the purpose of illustration.

\section{FMFM DETECTOR ELECTRONICS}

Each FMFM detector housing contains an electronics card for signal pulse shaping and counting [2] (see Figure 3). This front-end detector interface electronics card (DIEC) independently amplifies and shapes the detector signals coming out of the preamplifier before they are summed. The variable gain shaping amplifier (VGA) consists of $\mathrm{CR}^{2}-\mathrm{RC}^{5}$ two-pole low-pass filters [3] that generate a bipolar output signal with a zero-crossing time of about 2.5 microseconds. The signal is needed for the next-stage pulse-counting circuitry. The gain control of the shaping amplifier is accomplished by a 64-bit variable attenuator with an attenuation range of 5:1. The attenuator is controlled by the FMFM computer via a sensor network communication (SNC) card. The SNC card is included in the rear part of the DIEC design, as shown in Figure 7. The combined shaped signal from the dual detectors is fed into two parallel FMFM computer-controlled single-channel analyzers (SCAs). The signal from the summing amplifier (see Figure 6) is separated into low- and high-energy bands with these two SCAs; subsequently, each SCA provides the count rate for each energy band of interest. The SCAs generate digital transistortransistor logic (TTL) pulses ( $+5 \mathrm{Vdc}$ amplitude and $\sim 6$ microseconds wide) for data counting by the FMFM computer, as shown in Figure 7 . The detailed architectural design of the SCAs is given in ref. 4. The custom-made DIEC with surface-mounted components is shown in Figure 8. When the data acquisition cycle, which is a data collection period of 60 seconds, is started, the counts are read from the SCAs every 100 milliseconds and are stored in the SNC over 55 seconds. In the last 5 seconds, the collected data packet is sent to the FMFM computer for data processing. 
The commercially available SNC card (Echelon Corp., Palo Alto, Calif.), which acts as an on-board computer, provides the local area network node for secure-count data transmission to the FMFM computer (see Figure 8). In addition, the SNC card provides the computer gain control of the VGAs that is needed for the independent energy calibration of each of the detectors. In addition, each SNC has a unique programmed address that identifies the detector location on the detector assembly for consistent

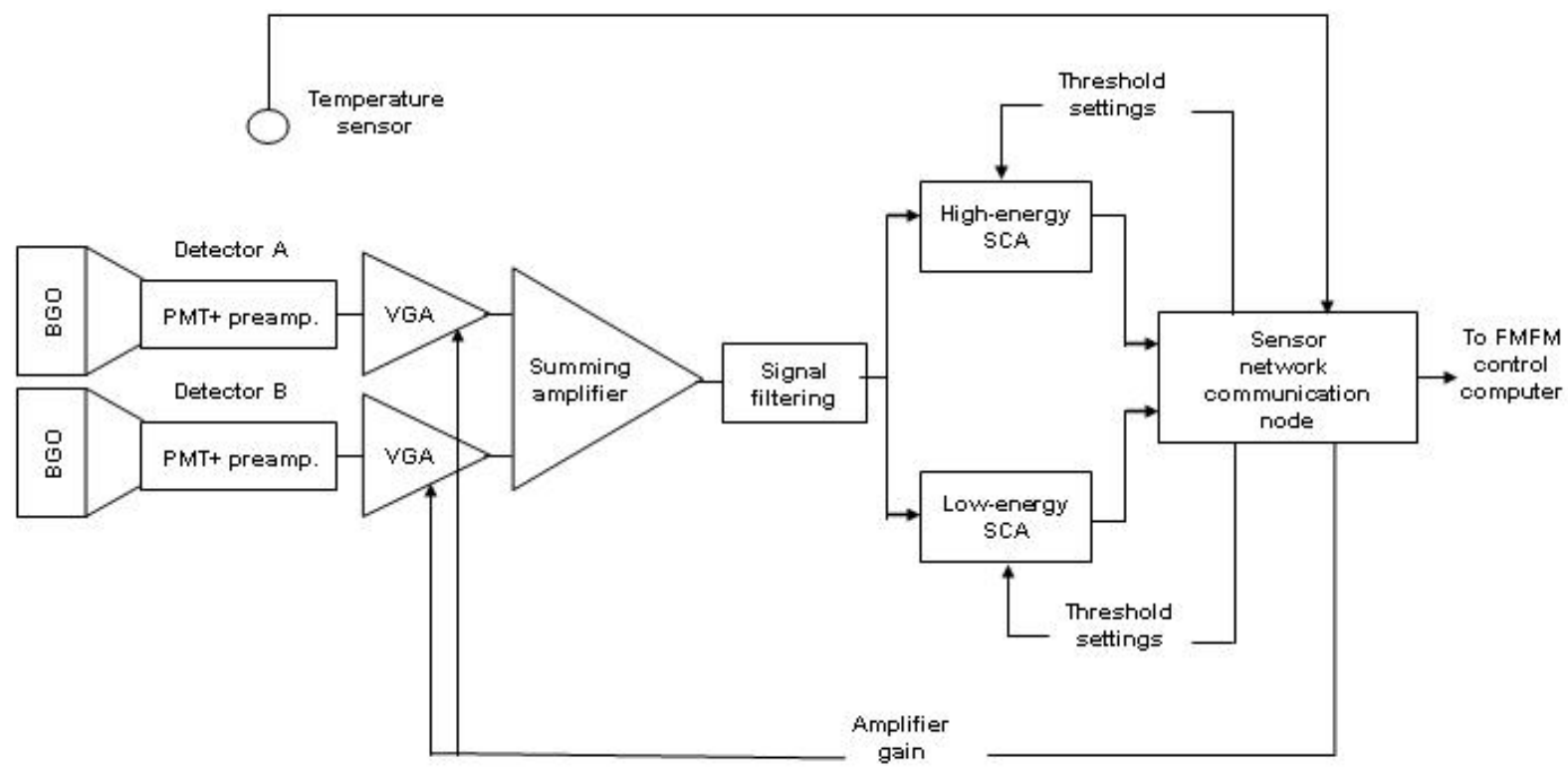

Fig. 7. Schematic block diagram of the FMFM detector electronics card (DIEC). VGA = variable gain amplifier with bipolar pulse shaping; SCA = single-channel analyzer; $\mathrm{PMT}=$ photomultiplier tube.

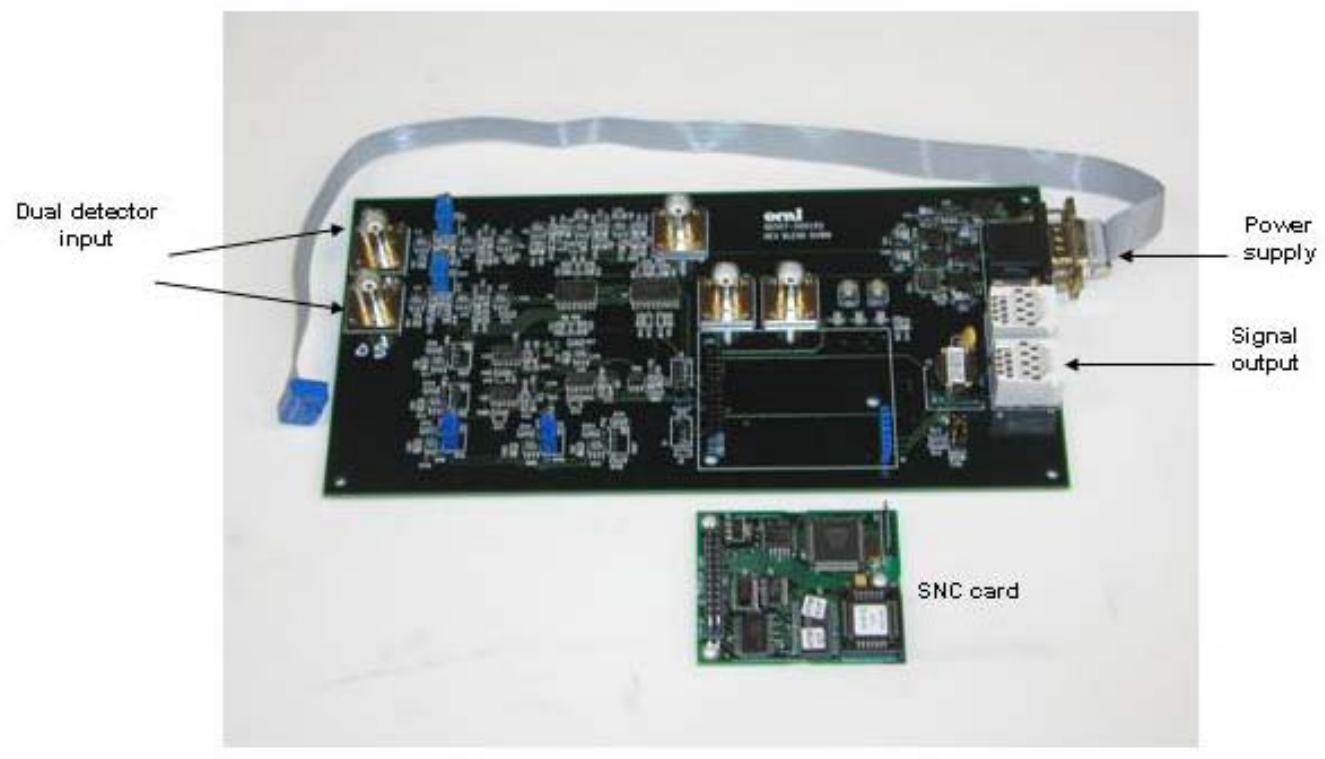

Fig. 8. The custom-made detector interface electronics card and the sensor network communication (SNC) card that mounts on it. 
FMFM data acquisition and recording. The SCA lower and upper energy thresholds (see Figure 9) of the energy band are also controlled by the FMFM computer via the SNC card. The higher-energy SCA is used for obtaining the counts for the measurement of the $0.3-$ to $2-\mathrm{MeV}$ delayed gamma-ray signal from the fission fragments in the $\mathrm{UF}_{6}$ stream.

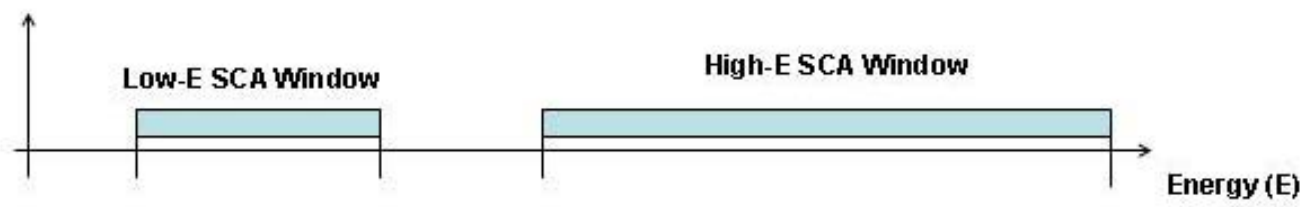

Fig. 9. FMFM detector system utilizes both low-energy and high-energy single-channel analyzers (SCAs). The high-energy SCA is used for the delayed gamma ray measurements $(>0.3 \mathrm{MeV})$. The low-energy SCA is used to perform the detector energy calibration by acting as a simple multichannel analyzer. It sets its energy window to a lower value (typically about $10 \mathrm{keV}$ ) and sweeps the window over its entire dynamic range $(\sim 500 \mathrm{keV})$.

The lower-energy SCA is set for the energy scan during the computer-controlled detector energy calibration to capture 186- or $96-\mathrm{keV}$ spectral lines from the $\mathrm{UF}_{6}$, depending upon its enrichment. When the FMFM computer is selected to perform the energy calibration, the lower-energy SCA is configured as a simple multichannel analyzer (MCA) by setting its energy window (see Figure 9 ) to a lower value (typically about $10 \mathrm{keV})$ and sweeping the window over its entire dynamic range $(\sim 500 \mathrm{keV})$. The operation of the DIEC requires $\pm 15 \mathrm{Vdc}$; its SNC card needs $+8 \mathrm{Vdc}$.

The signal response of the PMT and the BGO is very sensitive to local temperature variations. Local temperature measurements are provided by a sensor that is also a part of the DIEC (see Figure 7). As discussed in detail in ref. 4, the overall temperature response of the detector signal resulting from the intrinsic temperature coefficient of each BGOPMT detector assembly is known and is used for real-time correction of the detector response by monitoring the $186-\mathrm{keV}$ spectrum line of ${ }^{235} \mathrm{U}$ obtained with the lowerenergy SCA. The VGAs are adjusted accordingly to maintain the detector energy calibration. In addition, the aging of the PMT is corrected occasionally by using the builtin gain (5:1) adjustment of the VGAs; the technique is similar to that used for detector energy calibration. 



\section{FMFM DETECTOR SYSTEM ENGINEERING DESIGN CHARACTERISTICS}

The FMFM detector assembly detailed engineering design drawing is provided in Figure 10, and the cross-sectional view of the assembly is shown in Figure 11. Both the BGO crystal and the PMT are shielded with lead to reduce the room background signal, $N_{\mathrm{b}}$, resulting from inherent gamma ray emission from ${ }^{252} \mathrm{Cf}$ and radioactive capture gamma rays $(\sim 2.2-\mathrm{MeV})$ caused by the interaction of the source neutrons with the hydrogenous polyethylene. The shielding increases the signal-to-noise ratio (from the background radiation) and further improves the measurement convergence time, $\tau_{\mathrm{c}}$. The detailed view of the FMFM detector housing together with the DIEC is shown in Figure 12. Figure 13 shows the overall FMFM detector assembly and the detector signal power distribution box, where signals from all four detector subassemblies are summed before they are sent to the FMFM main computer for processing. It also shows where the highand low-voltage power supplies for the detectors are located.

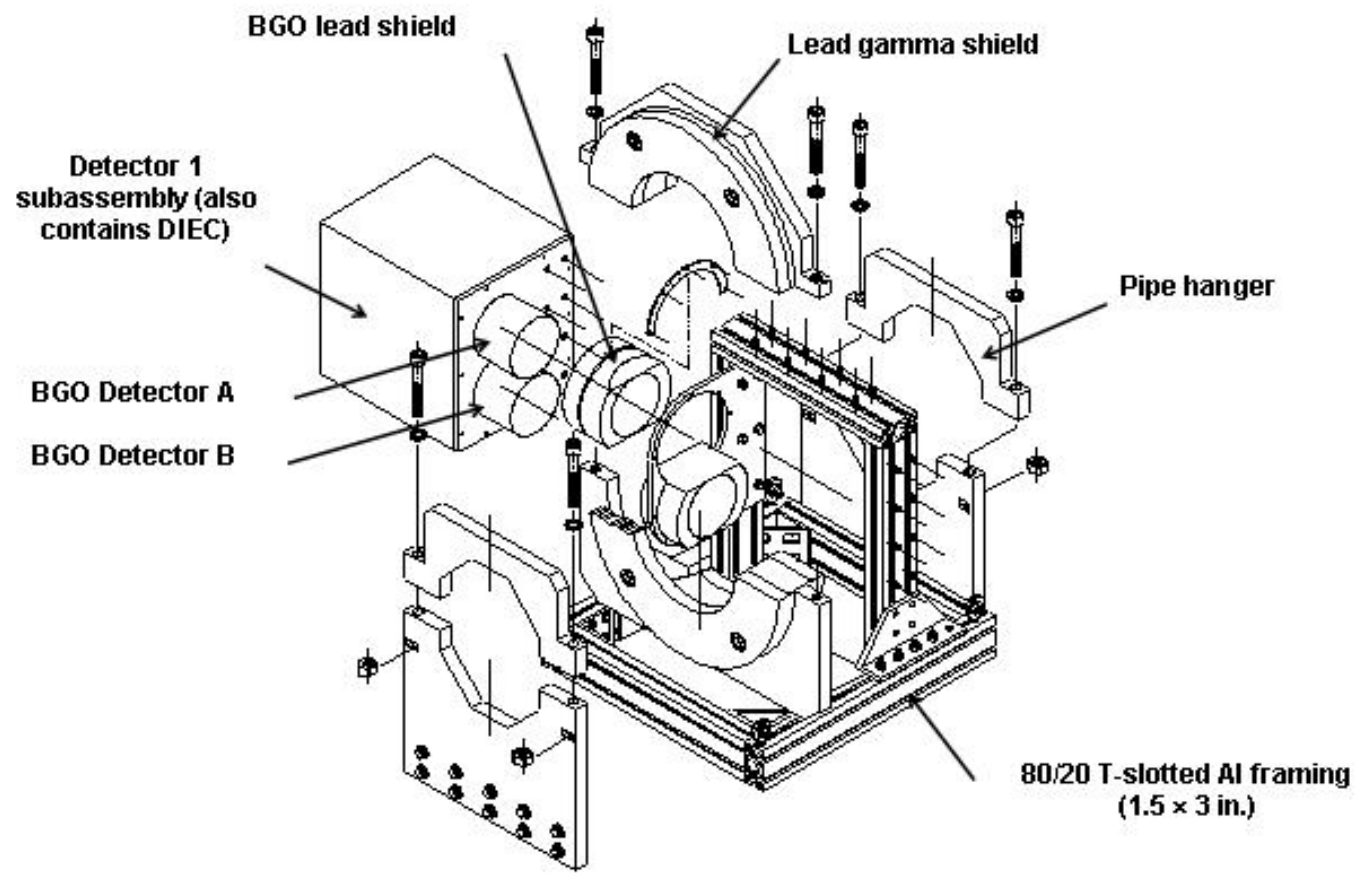

Fig. 10. FMFM detector assembly designed for 8-in.-diam $\mathrm{UF}_{6}$ process pipes. 


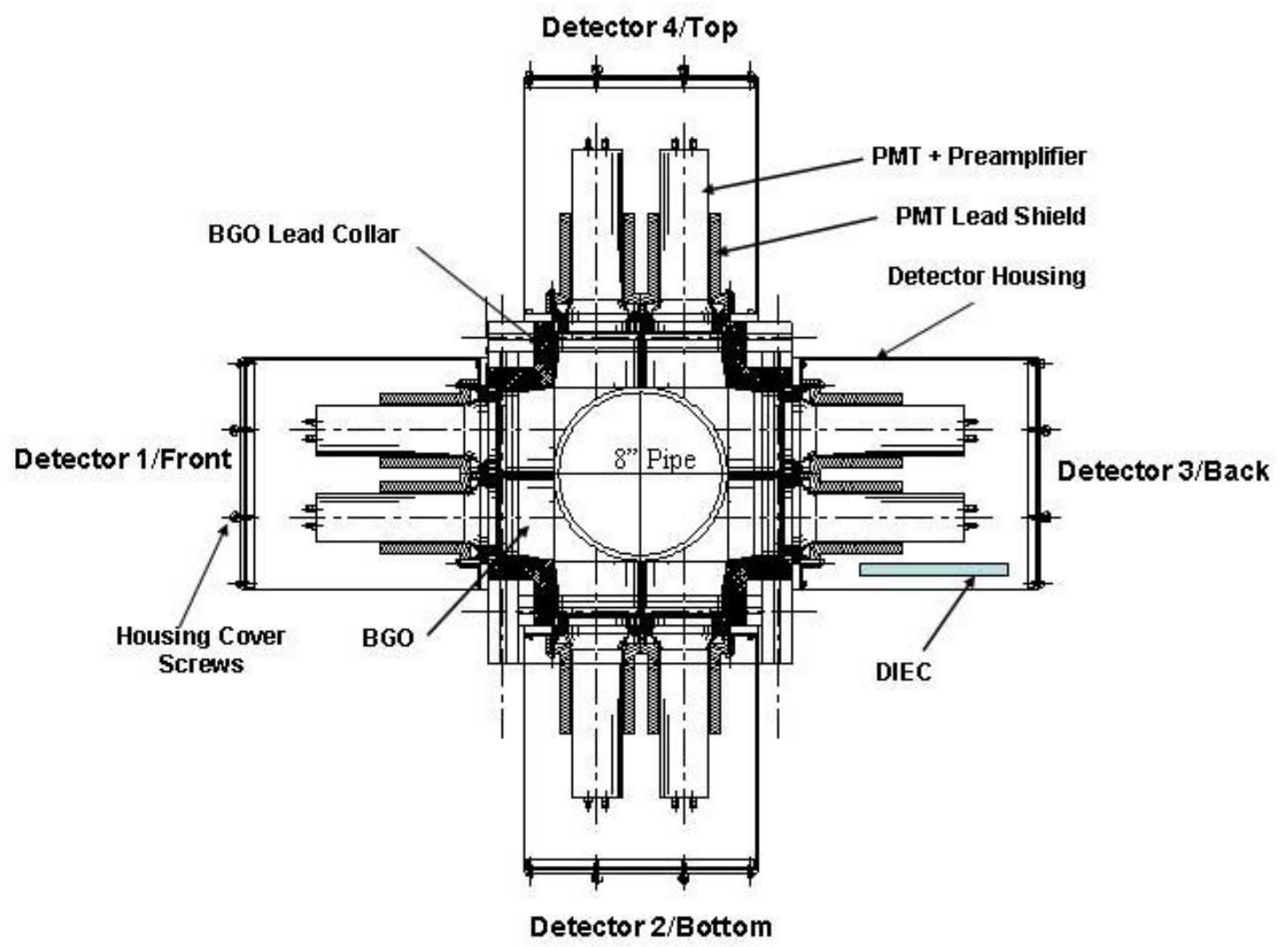

Fig. 11.Cross-sectional view of the FMFM detector assembly around the process pipe. 


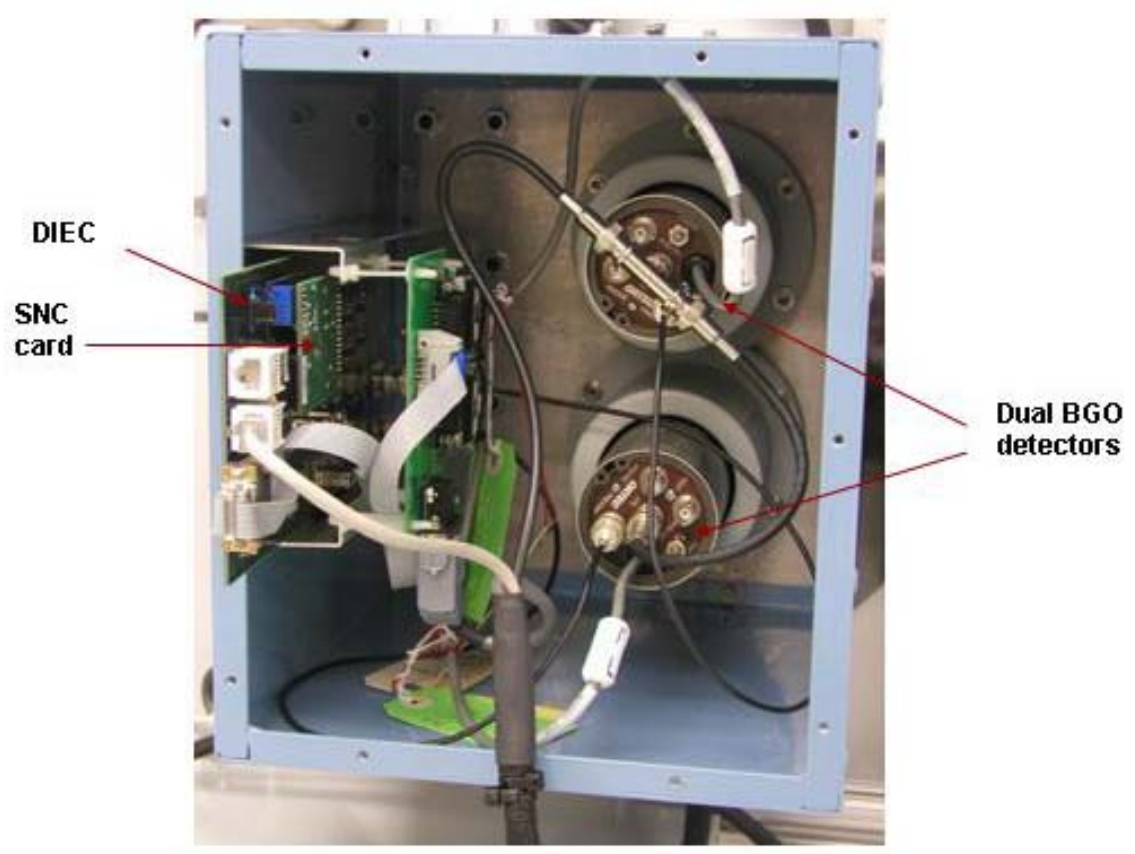

Fig. 12. View of the FMFM detector housing showing the detector interface electronics card (DIEC) and the sensor network communication (SNC) card.

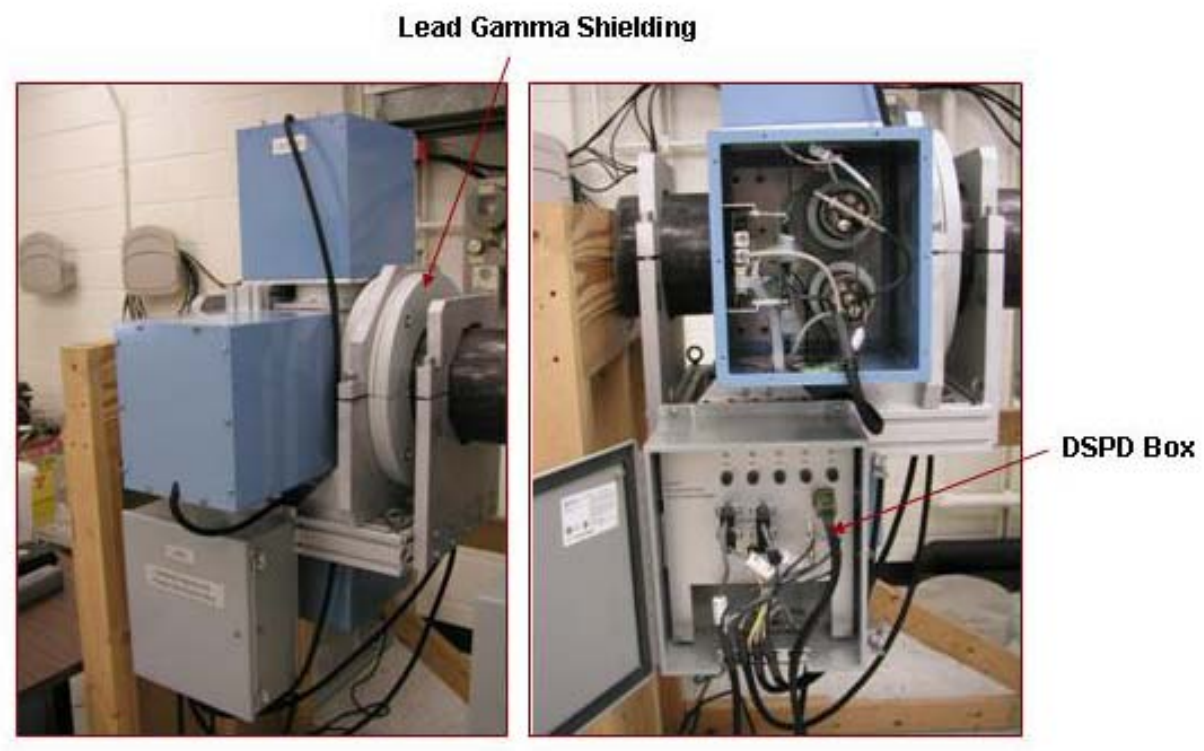

Fig. 13. View of the FMFM detector assembly showing the detector signal and power distribution (DSPD) box and the additional lead gamma shielding located near the FMFM sources. The added shielding reduces the detector background signal. 



\section{DUAL DETECTOR PERFORMANCE AND ENERGY CALIBRATION}

The dual detector system has been tested, and it has been verified that even at high count rates (> $5 \mathrm{kcps}$ ), the total pulse count from each of the SCAs shows a count degradation of less than $1 \%$ compared with the same pulse sources counted separately. During calibration, the lower SCA window is set to a narrow width and is swept over the entire dynamic range of the SCA. The gain for each detector channel is determined with the other channel gain set to zero. After the calibration sweeps are done, both channel gains are set to their required levels. Figure 14 shows the energy calibration of the dual detectors when a $4 \%$ enriched uranium sample is placed under the detectors. The characteristic $186-\mathrm{keV}$ spectral gamma ray peak of ${ }^{235} \mathrm{U}$ is clearly resolved and aligned for both detectors.
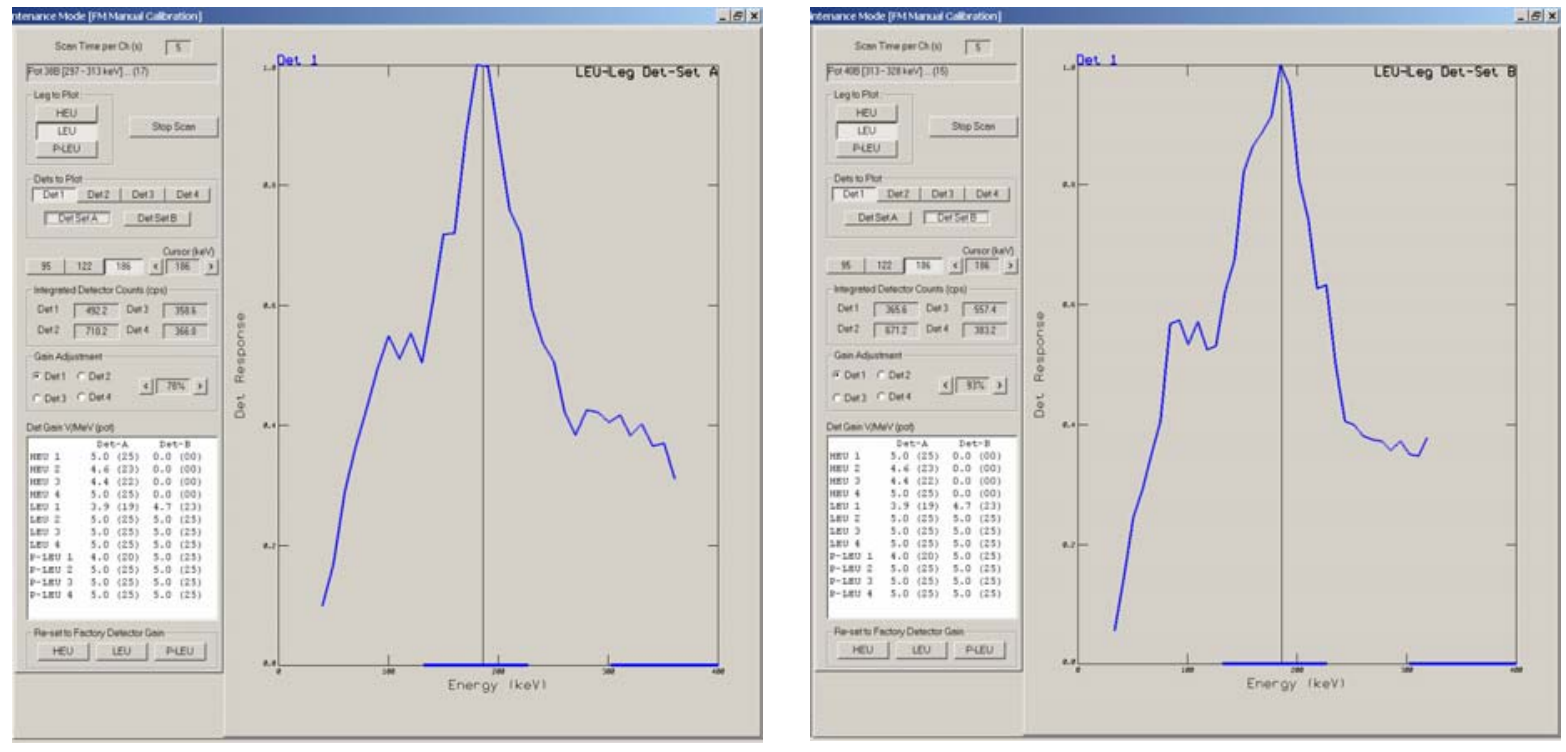

Fig. 14. Energy calibration plots for detectors $A$ and $B$ in the dual detector located in subassembly No. 1. The curves are the pulse-height spectrum for a $4 \%$ enriched uranium sample placed under the detectors. They show the characteristic $186-\mathrm{keV}$ line from the ${ }^{235} \mathrm{U}$. 



\section{CONCLUSION}

The FMFM detector design for 4-in.-diam process pipes has been successfully scaled up for 8-in.-diam process pipes. The dual-detector system design improves detection efficiency, thus enabling shorter measurement convergence times. The modified FMFM system will be field implemented in late 2004. 



\section{REFERENCES}

[1] J. March-Leuba et al., 38 ${ }^{\text {th }}$ Annual INMM Meeting, Phoenix, Arizona, July 20, 1997.

[2] G. P. Knoll, Radiation Detection and Measurements $3^{\text {rd }}$ Edition, John Wiley and Sons, New York, 2000.

[3] M. J. Paulus et al., $38^{\text {th }}$ Annual INMM Meeting, Phoenix, Arizona, July 20, 1997.

[4] M. J. Paulus et al., Nuclear Science Symposium, 1997. 



\section{ACKNOWLEDGMENT}

The authors wish to thank Richard W. Jones (Oak Ridge National Laboratory

Engineering Science and Technology Division) for his help with the mechanical design of the FMFM detectors. 

ORNL/TM-2004/114

\section{INTERNAL DISTRIBUTION}

$\begin{aligned} 1 . & \text { C. R. Brittain } \\ 2-6 . & \text { K. Castleberry } \\ 7 . & \text { J. A. March-Leuba } \\ 8-12 . & \text { D. H. Powell } \\ 13-17 . & \text { T. Uckan } \\ 18 . & \text { J. D. White } \\ 19 . & \text { J. Johnson, OTIC }\end{aligned}$

\section{EXTERNAL DISTRIBUTION}

20. Guy Armantrout, Lawrence Livermore National Laboratory, U. S. Department of Energy, NA-23/Germantown Building, 1000 Independence Avenue, S. W., Washington, DC 20585

21. Janie Benton, U. S. Department of Energy, NA-23/Germantown Building, 1000 Independence Avenue, S.W., Washington, DC 20585-1290

22. Dianna Blair, Sandia National Laboratory, International Programs, 10600 Research Road, Albuquerque, NM 87123

23. Cynthia Boggs, Argonne National Laboratory c/o 270 Complex, 19901 Germantown Road, Germantown, MD 20874

24. Donald Close, Los Alamos National Laboratory, MS J562, Bikini Atoll Rd., SM 30, Los Alamos, NM 87545

25. David Dougherty, Brookhaven National Laboratory, U. S. Department of Energy, NA-241, 1000 Independence Avenue, S.W., Washington, DC 20585

26. Melvin Feather, II, SAIC, 20201 Century Blvd., Ste. 300, Germantown, MD 20874

27. Joseph Glaser, U. S. Department of Energy, NA-232, 1000 Independence Avenue, S.W., Washington, DC 20585

28. Tom Hill, Los Alamos National Laboratory, MS J562, Bikini Atoll Rd., SM 30, Los Alamos, NM 87545

29. Kenneth Lewis, DOE/NBL, New Brunswick Laboratory, 9800 S. Cass Avenue, Argonne, IL 60439

30. Edward Mastal, U. S. Department of Energy, NA-232, 1000 Independence Avenue, S.W., Washington, DC 20585

31. Calvin Moss, Los Alamos National Laboratory, MS J562, Bikini Atoll Rd., SM 30, Los Alamos, NM 87545

32. Radoslav Radev, Lawrence Livermore National Laboratory, P. O. Box 808, Livermore, CA 94551

33. Robert Richmond, Bechtel Nevada, P. O. Box 380, Suitland, MD 20752

34. Kurt Siemon, Jr., U. S. Department of Energy, DOE/NA-241, 1000 Independence Ave., S.W., Washington, DC 20585

35. David Wall, U. S. Department of Energy, NNSA, Y-12 Site Office, MS 8009, 200 Administration Road, Oak Ridge, TN 37831 
